\title{
EMERGENCY MANAGEMENT SYSTEM FOR College STUDENTS BASED ON Big DATA Processing TECHNOLOGY
}

\author{
Ziyue wang ${ }^{1}$, Tingfang $\operatorname{li}^{1}$ and Jianxia chen ${ }^{2}$ \\ ${ }^{1}$ Major in data science and big data technology, \\ Hubei University of Technology, China \\ ${ }^{2}$ Associate Professor, School of computer science, \\ Hubei University of Technology, China
}

\begin{abstract}
Since 2020, the epidemic of Corona Virus Disease 2019 has swept the world, which has had a great impact on people's life. Especially for college campus life. This paper presents an emergency management system for college students. We use Java Web, big data processing and other technologies to develop, implement and test the system. The system integrates daily management and emergency management, which can meet the basic needs of teachers and students on campus. We hope to provide convenience for students and teachers in learning and management.
\end{abstract}

\section{KEYWORDS}

Web System, Stream Data Processing, Data visualization, Internet Worm.

\section{INTRODUCTION}

At present, how to respond quickly to emergencies has been paid more and more attention by various countries. How to make the fastest response to natural disasters, emergency traffic accidents, public health emergencies and so on to ensure the safety of personnel and reduce property losses has become a problem that all countries are thinking about. With the development of the Internet, China has entered an era of rapid development of information technology. China's large population base and strong personnel mobility promote economic prosperity and development, but also make the risk spread more quickly.[2] At present, China is in a critical stage of development. The research and application of emergency management system plays a very important role in social development and people's livelihood.

Emergency management system is mainly used in natural disasters, public health, transportation and other fields. There are still many problems in the practical application of the current emergency management system. For the real-time information collection, processing and decision-making efficiency is not high, the emergency information release system is not perfect, there are obvious shortcomings and deficiencies in the information release channels. Facing the national population, the timeliness and dissemination of information is insufficient. In fact, the application scope and population of emergency system are far more than the above. At present, the scale of personnel training in Colleges and universities is expanding, and the number of college students is also increasing. Whether college students can correctly deal with emergencies

David C. Wyld et al. (Eds): SOFEA, CTCM, BIBC, SIPR, NCWC, CSEN, EDTECH - 2021 
affects the campus order and social order. [1] Especially during the novel coronavirus pneumonia, schools need to grasp the geographic location, health status, mobile trajectory and other information of teachers and students in time. But in fact, the efficiency of adopting excel forms and filling out paper forms is low. In the process of information transmission, there will also be problems such as information loss, errors and timeliness reduction. To solve these problems, this paper uses real-time data processing, data visualization and other technologies to obtain geographic location information and health status information. At the same time, it adds daily management functions to the system, which provides convenience for teachers and students.

\section{RELATED WORK}

\subsection{Emergency management system for College Students}

Emergency management refers to a set of theory and method system that managers, in order to reduce the harm of emergencies, scientifically analyze the causes, occurrence and development mechanism of emergencies and their negative effects, integrate all aspects of social resources, and effectively deal with, control and deal with them. [5]

College students emergency management system can be divided into eight functional modules. The system not only completes the emergency management, but also adds the daily management of students, which provides great convenience for students and teachers.

User management module: users can login and register, and view and modify personal information on personal page.

Daily check-in module: users fill in the check-in form to complete the information collection, and store the information in the database.

Track positioning module: according to the geographic location information of the login user collected in the database, the system draws the activity track map of the user in recent 14 days. The system obtains the current geographic location information of the user when the user logs in, and displays the current location of the user on the map.

Epidemic distribution module: make the heat map according to the current national epidemic data.

Grade management module: student users can query the grade table of each semester in this module, and the system adopts visual means to display the student grade information on the page in this module. Counselor users can query the transcripts of all students and the visualization of each subject.

Activity management module: in this module, ordinary student users can view the time and place of the activities recently released by the school, and counselor users can also publish activities.

Empty classroom query module: users can select the number of weeks, week and teaching building to query the corresponding empty classroom.

Information display module: in the information display module, users can view the teacher team information, system introduction and development team information. 


\subsection{Introduction of Stream Data Processing Technology}

Stream data is a real-time, continuous, potentially unbounded, uncertain, time-varying (implicit through the arrival time or explicit timestamp) sequence of data items, also known as stream data. Streaming computing is one of the two main processing modes of big data. Streaming computing needs to provide continuous and dynamic services for the data flowing into the system dynamically, and needs real-time computing for the streaming data.

According to the different timeliness of data processing pursued by flow computing, stream data processing can be divided into batch processing model and continuous operator model. The main goal of batch processing model is high throughput, while the main goal of continuous operator model is low latency.

\section{REQUIREMENT ANALYSIS}

\subsection{Functional Requirement}

Real time positioning function: after the user logs in, the system automatically obtains the user's current geographic location information and marks it on the map.

Daily check-in function: users submit geographic location information and health status information by filling in the form.

Information visualization function: in the daily grade management, track positioning and epidemic distribution module, the visualization function is used. Different modules need to determine the visualization form according to their specific conditions.

Daily management function: daily management includes activity management, empty classroom query, grade management and other functions to meet the daily needs of students and teachers.

\subsection{Performance Requirements}

Real time: the system needs to obtain the user's real-time location information, which requires the system to have the characteristics of real-time.

Security: it can protect the system from malicious attacks and protect the user's information privacy from disclosure.

Maintainability: the system needs to be able to maintain and upgrade when the amount of access is too large or other situations occur.

\subsection{Feasibility Analysis}

This system uses eclipse as the development tool, MySQL database and SSH framework to set the overall system architecture. In the stream data processing function, a big data platform based on flume + Kafka + storm + zookeeper + MySQL is built, which is feasible from the technical point of view. 


\subsection{Overall Framework Design of the System}

The system adopts SSH framework in MVC mode, which is composed of struts, spring and hibernate. Struts can act on the presentation layer to simplify data access in various scopes and realize fast verification. Hibernate acts on the persistence layer to provide efficient mapping relationship between different objects. Spring is mainly used in the business logic layer to complete the program design and development with complex business logic. [3] The overall design of the system is shown in the figure:

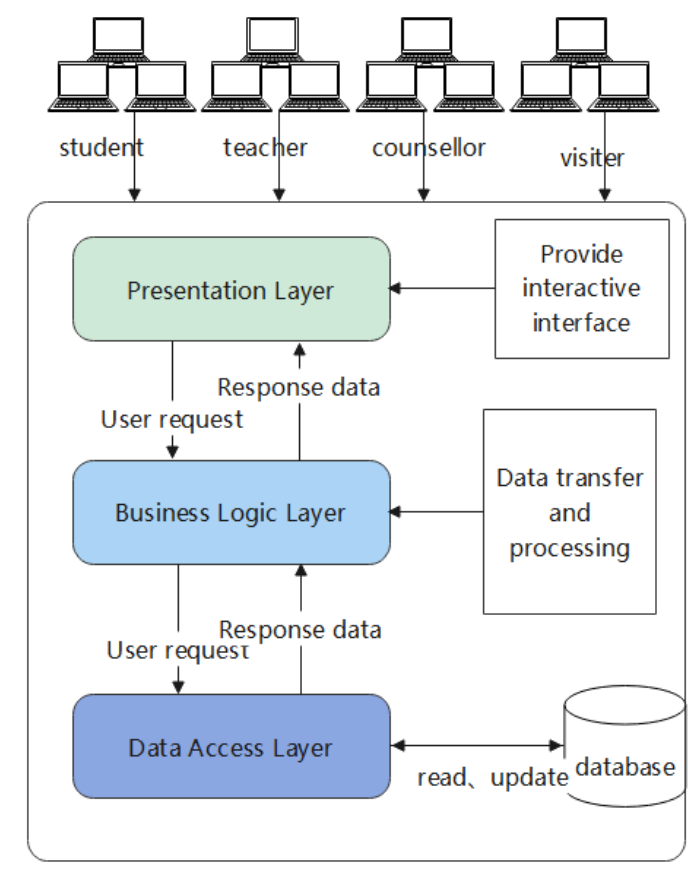

Figure 1. Overall Design of the System

\subsection{System Overall Function Design}

As shown in the figure, the system consists of seven main modules: user management, empty classroom query, score query and so on. Each module can be divided into several sub blocks.

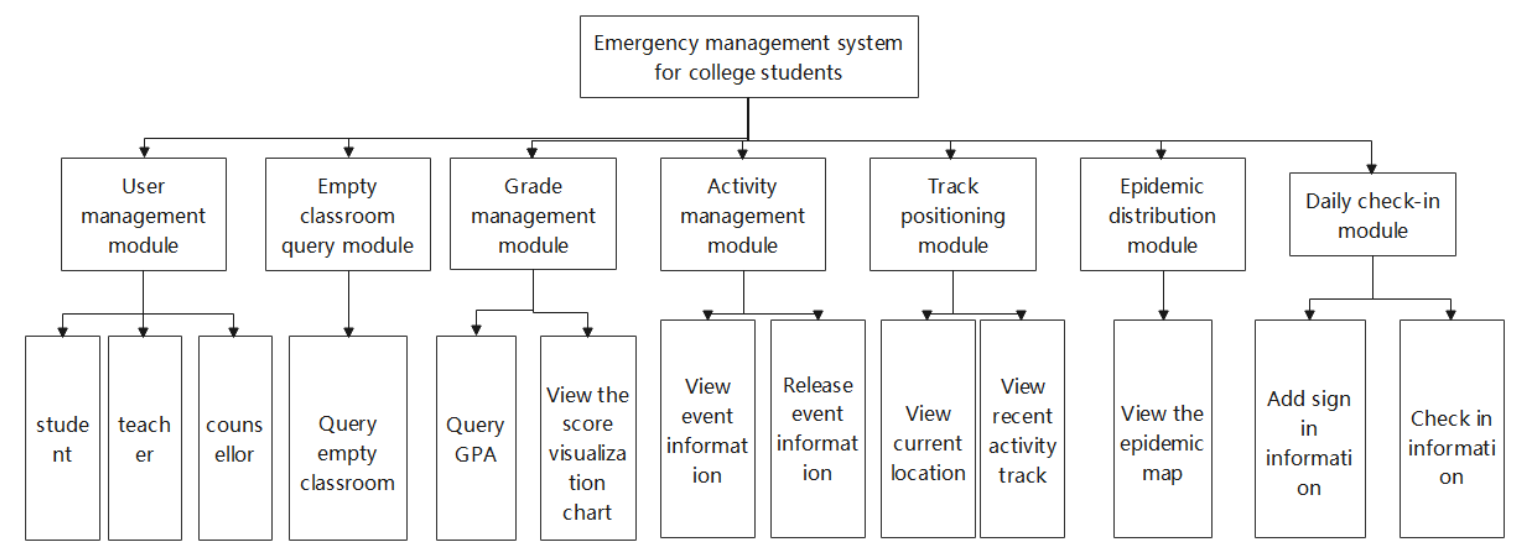

Figure 2. System Overall Function Design 


\subsection{Detailed Design}

\subsubsection{Track Positioning Module}

The module includes real-time positioning and active track. Real time positioning obtains the user's IP when the user logs in, stores the IP and the corresponding geographic location information in the database, finds the user's geographic location in the database for nearly 14 days in the activity track module, and visualizes the activity track to display on the front page.

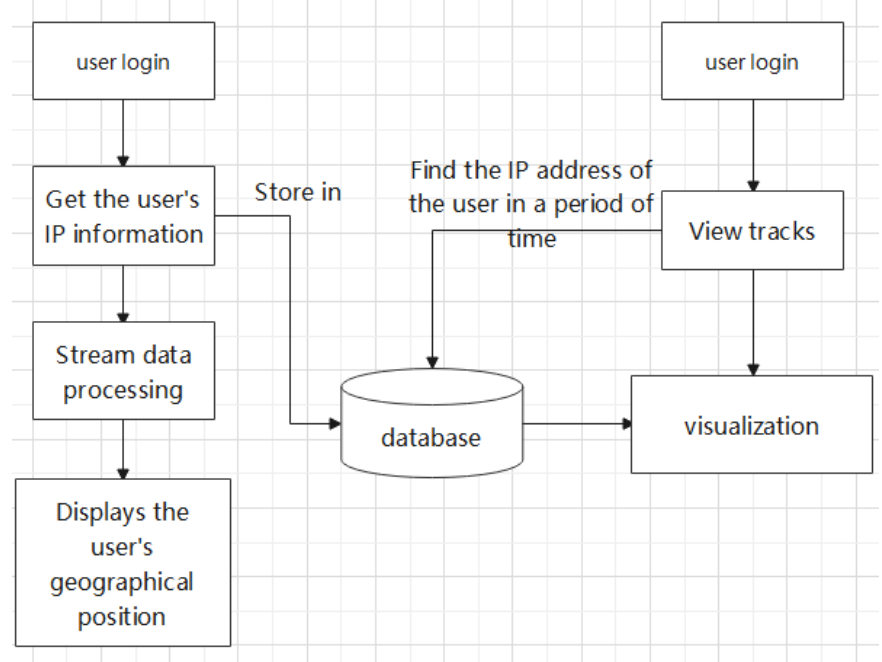

Figure 3. Track Positioning Module

\subsubsection{Epidemic Distribution Module}

In this module, the epidemic data is crawled through Python crawler technology, and the data is displayed in the form of thermal map visualization after processing.

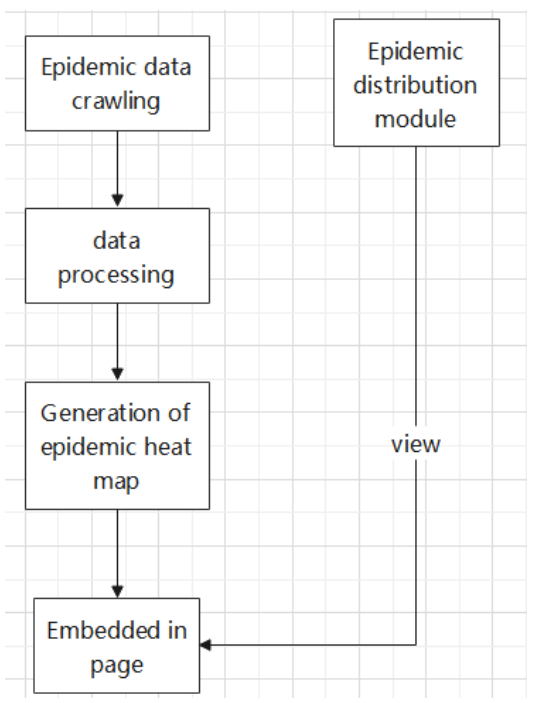

Figure 4. Epidemic Distribution Module 


\subsubsection{Daily Check-in Module}

In this module, the user needs to fill in the basic health information table. The basic information of the table can be queried from the database and returned to the page. After the user completes the health information of the day, click submit to save the information to the database. The collected information of students' status is displayed on the counselor side.

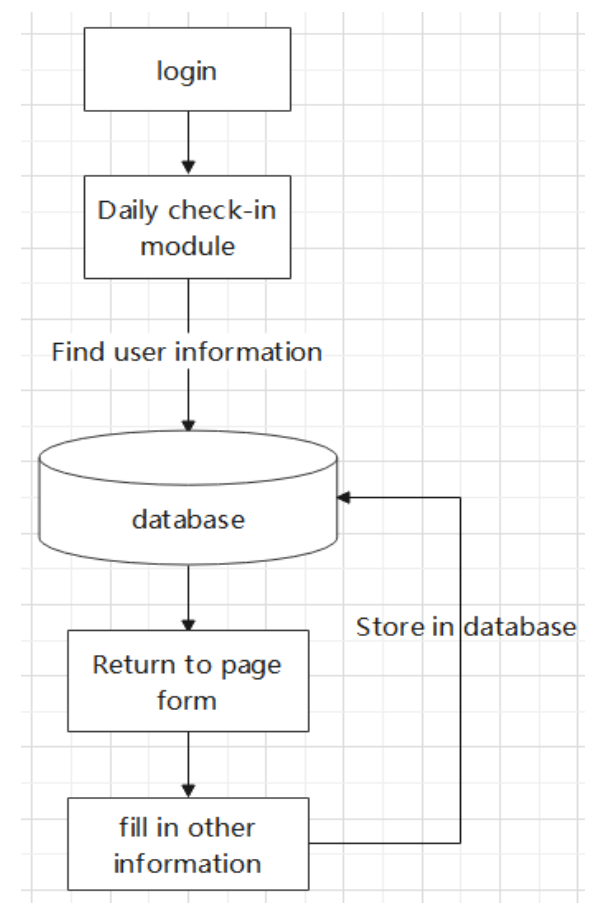

Figure 5. Daily Check-in Module

\subsubsection{Grade Management Module}

In this module, different users can query the grade data they need. Students can log in to query visual results of their grades, GPA, comparison between grades and grades. Teachers can query the students' grades and their visual results. Counselor users can view the visual results of all students' scores in various subjects and grades.

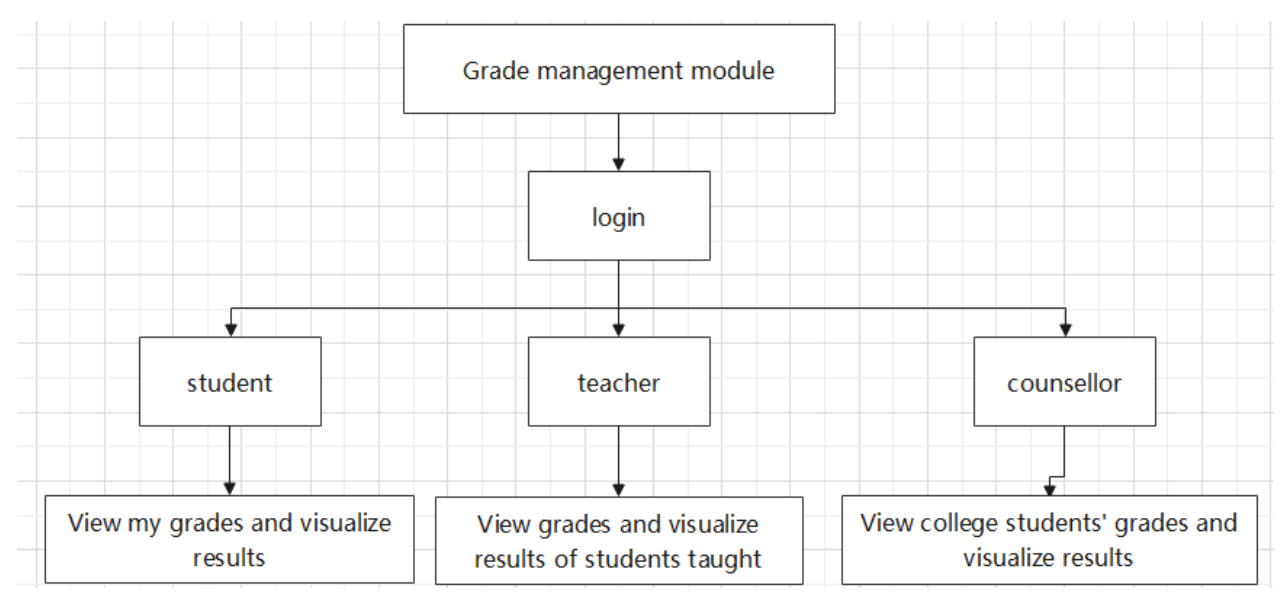

Figure 6. Grade Management Module 


\subsubsection{Empty Classroom Query Module}

In this module, users can query all the empty classrooms of a certain teaching building in a certain period of time.

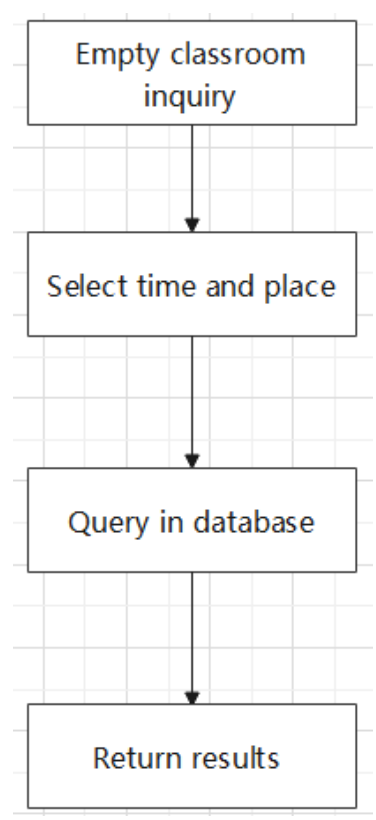

Figure 7. Empty Classroom Query Module

\subsubsection{Activity Management Module}

In this module, ordinary student users can view the time and place of the activities recently released by the school. Counselor users can view the activity information and release activities on demand.

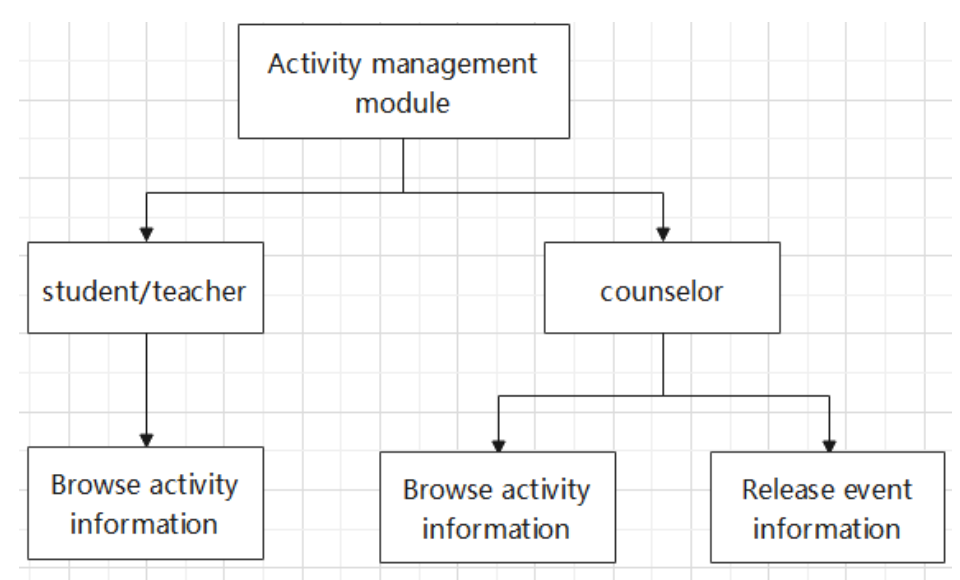

Figure 8. Activity Management Module

\subsubsection{Information Display Module}

This module includes the display of teacher information, system introduction and development team information. 


\subsubsection{User Management Module}

In the user management module, users can login and register, and view and modify personal information on the personal page. The system background can add and delete users directly.



Figure 9. User Management Module

\section{SYSTEM IMPLEMENTATION}

\subsection{Internet Worm}

Python language to write crawler program is an important way of data collection and analysis in the era of artificial intelligence big data. [4]This system uses Python language to design crawler . It crawls a large number of resources and information from the web page, and analyzes the epidemic visualization based on massive data. At the same time, in the student information management module, the system provide the information of teachers by crawling the information and contact information of college teachers on the school's official website for users to get contact with teachers. 


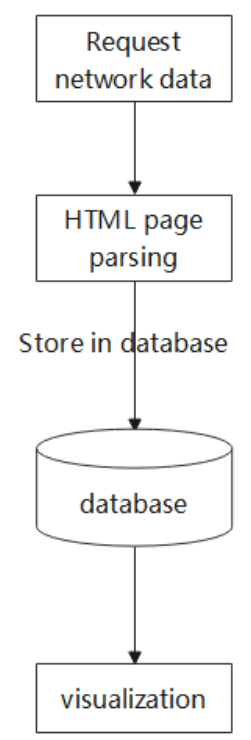

Figure 10. Internet Worm Process

\subsection{Stream Data Processing}

The real-time positioning part of the project uses big data stream processing technology. In order to realize the real-time response of the location information generated by the front-end users' login and check-in, we take the login and check-in event data as the event flow, and build a big data platform based on flume + Kafka + storm + zookeeper + Mysql to collect and process the event stream data in real time, and the data has been persistent and visualized. The overall framework is shown in the figure:

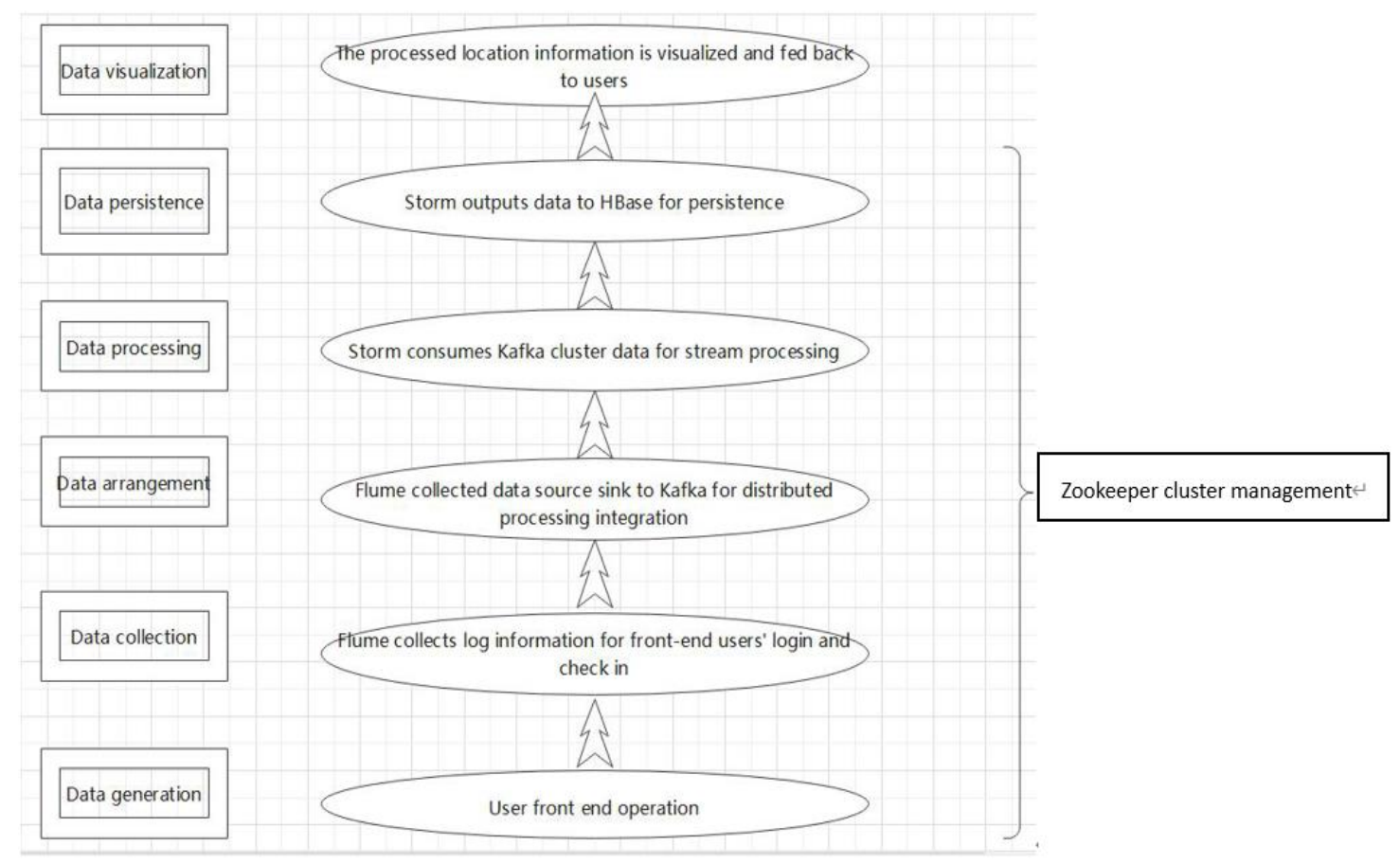

Figure 11. Stream Data Processing 
Kafka and storm are the most important parts, and the main difficulties lie in the realization of data production, data consumption, data persistence and application scheduling. The system uses flume to monitor the customized log to collect the IP address, time and other data generated when users $\log$ in to the system in real time. The collected source data is sorted and transmitted to storm in the form of stream data through Kafka. In the storm part, the highly integrated Trident framework is used to realize the business logic. The Trident framework retains the accuracy and integrity of the data, In IP location, the IP geographic location library provided by Alibaba cloud is used to convert the IP address to geographic location, and then the geographic location and user basic information are synchronized and persisted to MySQL database for data processing and visualization.

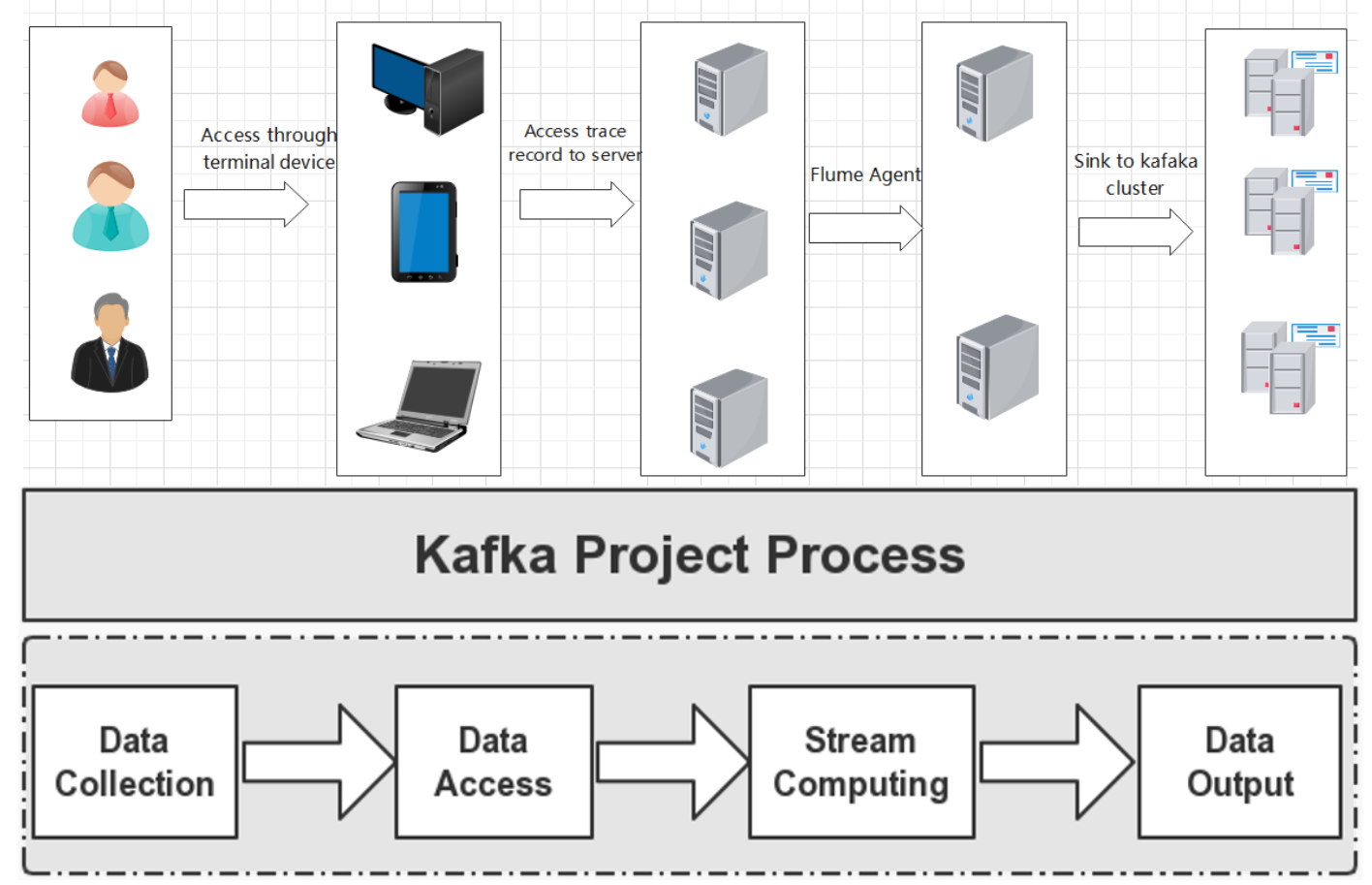

Figure 12. Kafka Project Process

\subsection{Data Visualization}

The purpose of data visualization is to visualize the abstract information content by means of graphics, so as to convey and communicate information clearly and effectively. In the visualization part of the system, the data visualization technology is widely used. The data of the epidemic is visualized in the form of scatter chart, color scale chart, sun chart and so on. The realtime data of the number of people diagnosed in all parts of the country is used to make the epidemic map, so as to clearly convey the intuitive feelings and information to users. In this project, many rendered HTML web pages are used to display the epidemic data. We also use the visualization method to show in several functions of the daily management.

\subsection{Web Implementation}

The web system has four kinds of permissions: student user, teacher user, instructor user and tourist. Visitors can enter the system visitors page to view the basic information of the home page, student users, teacher users and counselor users can use all the functions of the system. Different authorities have different functions in activity management, grade management and 
track positioning. Different functions are linked by the page navigation bar, and the webpage is embedded with links that can jump through the page to achieve redirection access.
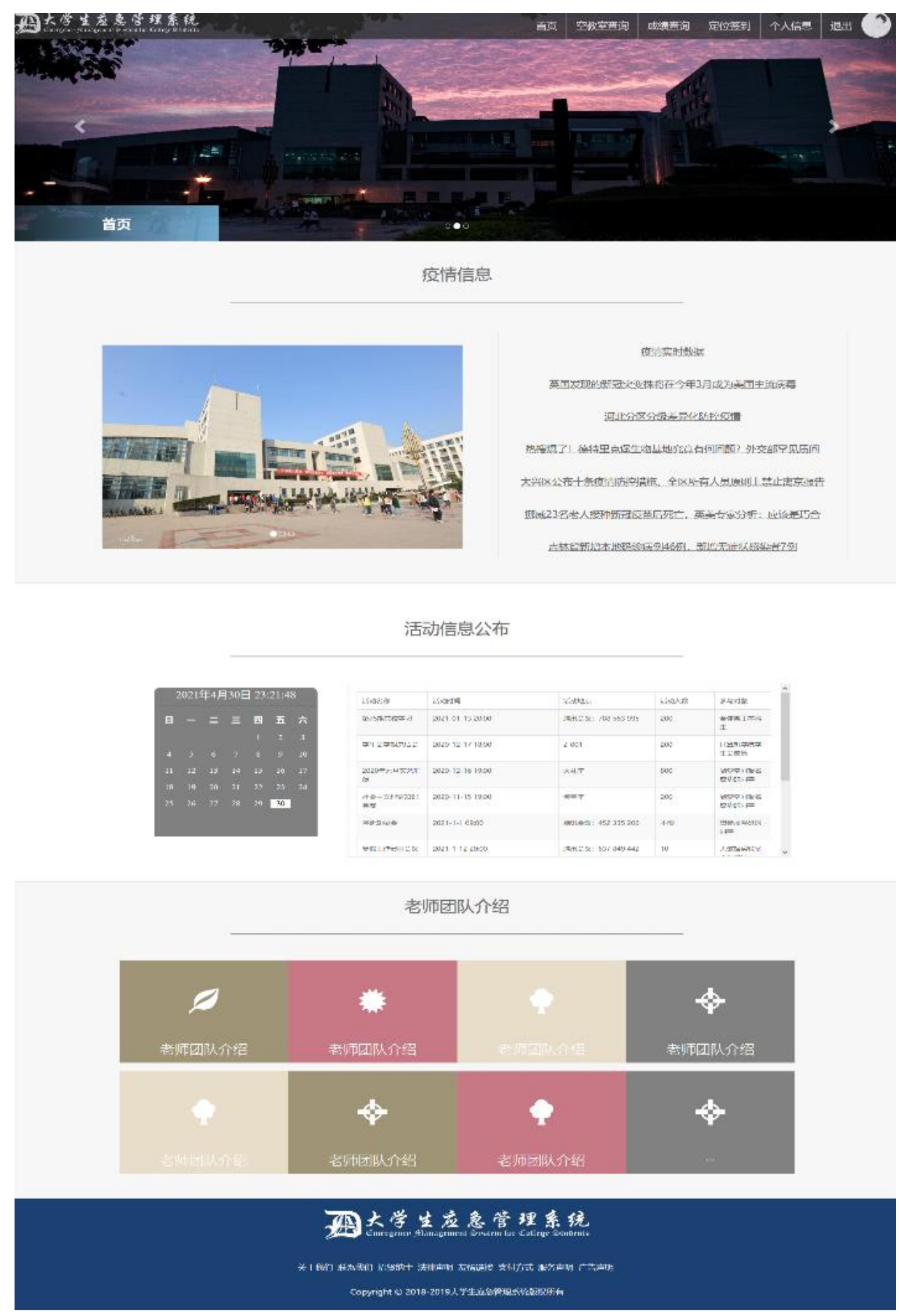

Figure 13. Webpage of the System

\subsection{Deficiencies and Prospects}

There are still some deficiencies in the current system, and we hope to improve it in the future. In the Grade management function, the results of data visualization are relatively rough, mostly in the form of tables and line charts, and the amount of data is relatively small. In the future, a grade 
analysis module can be specially made for grade management to help users analyze grades with more diversified visualization forms and more comprehensive grade data. In the function of tracking Position information, the geographic location range of users we can locate is not accurate enough. In subsequent improvements, this function can be further expanded. For example, the system can collect and sort out the location information in recent 14 days and compare it with the existing risk areas, screen the users passing through the risk areas, and return the user information to the manager page. In the framework of the system, we can also try to use Vue framework.

\section{Conclusions}

Emergency system has been applied in natural disasters, public health, transportation and other fields, but there are few emergency management systems for college students. The current emergency system still has a lot of room for improvement in real-time and big data processing. The emergency system for college students proposed in this paper opens up a new way in the emergency system in terms of real-time and data processing. The application of big data technology makes the system more intelligent and practical. At the same time, the combination of web crawler and data visualization technology makes the information on the page of the system richer and have a better visual effect. Based on demand analysis, we combine daily management and emergency management to make the system more widely used. Using java web technology and SSH framework we complete the page design and function development. Of course, we also hope to continue to improve the areas that can be expanded mentioned in the article and provide help for emergency management.

\section{REFERENCES}

[1] Guirong Zhang. Research on emergency management of college students in emergencies [J].Chinastaff education, 2013,18:122-122 + 124. [张桂荣. 高校大学生突发事件应急管理的研究 [J]. 中国职工教育,2013(18):122+124.]

[2] Qianqian Ma, Wenjuan Wang, Chunxia Yuan and COVID-19: Reflections on the construction of spatial health system in Colleges and Universities -- Taking Lanzhou City College as an example [J].Journal of Gansu Normal University, 2020,25 (05): 98-101.[ 马倩倩,王文娟,袁春霞.新冠疫情视 角下高校空间健康体系的构建与思考——兰州城市学院为例 [J]. 甘肃高师学报 ,2020,25(05):98-101.]

[3] Hailang Chen. Design and implementation of comprehensive petition platform based on SSH framework [J]. Electronic technology and software engineering, 2019, (15): 32-33[陈海郎. 基于 SSH 框架的信访综合平台设计与实现[J].电子技术与软件工程,2019(15):32-33.]

[4] Baogang Zhang. Research on web crawler and anti crawler technology based on Python [J]. Electronic world, 2021，(04): 86-87[张宝刚. 基于 Python 的网络爬虫与反爬虫技术的研究[J].电子 世界,2021(04):86-87.]

[5] Xiaolong Liu, Wen Zhao. Research on College Students' group emergency management system [J]. Journal of Beijing University of Aeronautics and Astronautics (SOCIAL SCIENCE EDITION), 2011, 24 (03): 24-29[刘小龙,赵雯.大学生群体突发事件应急管理系统研究[J].北京航空航天大学学报( 社会科学版),2011,24(03):24-29.] 
AUTHORS

Ziyue Wang Majored in data science and big data technology in the school of computer science, Hubei University of technology. Enthusiastic and cheerful, diligent and serious in study, won scholarships from Hubei University of technology for many times, and actively participated in discipline competitions and scientific research projects.

Tingfang Li A junior majoring in data science and big data in the school of computer science of Hubei University of technology. He mainly studies the direction of Java Web, won the third prize in the "Challenge Cup" competition, and "excellent student engineering assistant" of the student. development and service center of the University.

Jianxia Chen Associate professor and master tutor of the School of Computer Science, Hubei University of Technology. Research direction: cloud computing and big data, knowledge graph and natural language processing, intelligent planning research.
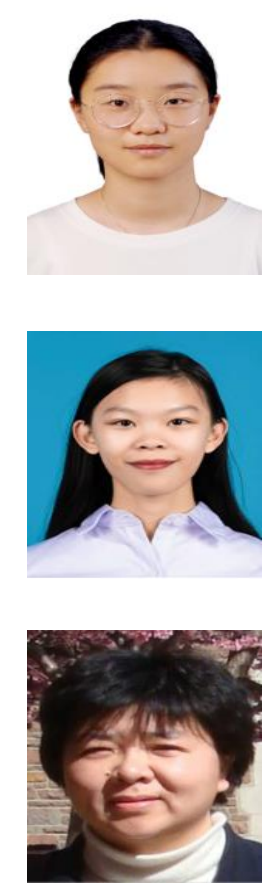

(C) 2021 By AIRCC Publishing Corporation. This article is published under the Creative Commons Attribution (CC BY) license. 